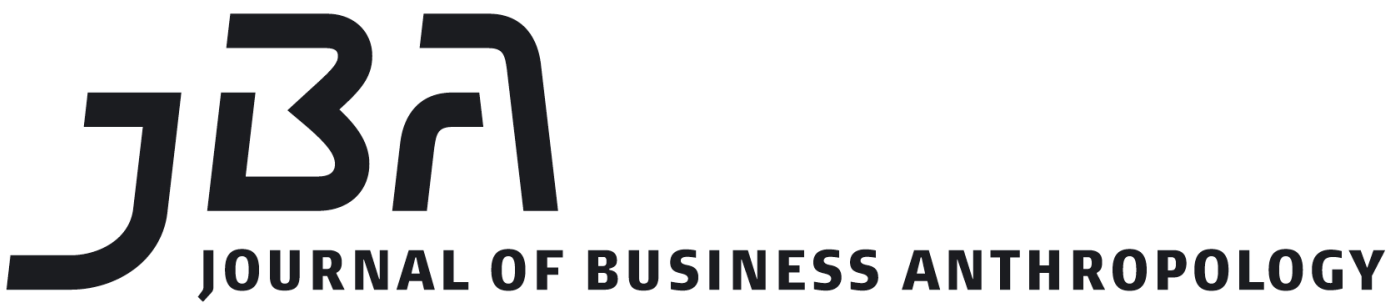

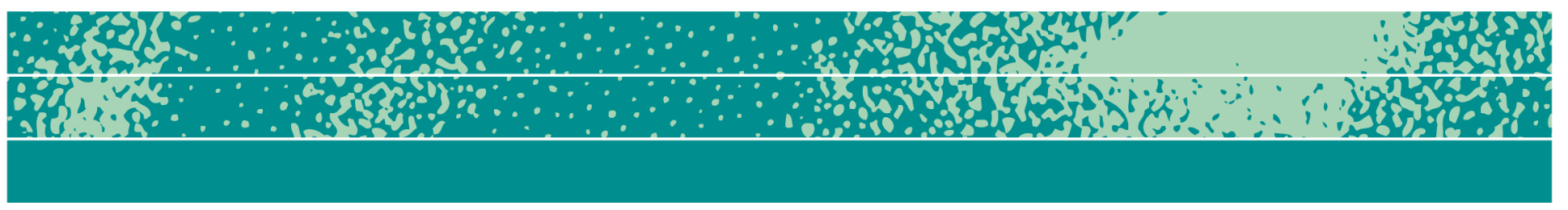

\section{Anthropologist in Advertising Agencies: Mediating Structures of Power and Knowledge Capital by Managing Relationships}

\author{
Timothy de Waal Malefyt
}

\begin{abstract}
This essay discusses how working from within an advertising agency as an anthropologist yields particular advantages in terms of presenting anthropological insights and gaining access to information that one would not have been privy to, compared to a study of advertising from the outside. Working from within an agency affords access not only to forms of objective data and consumer research documents that are less accessible from the outside, but also to forming critical relationships and subjective associations with clients that produce knowledge practices and situate information in authoritative positions of power from within. I draw on fifteen years of experience as a corporate anthropologist working within and among relationships in advertising which define, produce and sustain various structures of power and knowledge capital that orient insights and information in critical ways.
\end{abstract}

\section{Keywords}

advertising, consumer research, fieldwork, frame analysis, relationship management.
Page 1 of 13

JBA 6(1): 89-101

Spring 2017

(C) The Author(s) 2017 ISSN 2245-4217

www.cbs.dk/jba 


\section{Introduction}

How is knowledge produced, reproduced and extended in systems of power, such as in the advertising industry? Are there forms of knowledge to which an insider might be privy and an outsider excluded that shape the advertising agendas, economies of scale, and forms of production informing corporate practices and perceptions of consumers? Since forms of knowledge are not all equal, but in fact, implicate systems of power that produce knowledge (Foucault 1980), these questions have particular relevance for practicing anthropologists working inside and outside of industry. As an anthropologist who was employed long-term in an advertising agency, I observed how forms of knowledge served not only to promote commodity production, but also to enhance particular social interactions among contributors and corporate clients that are the authorities responsible for creating such commodities. One area in which knowledge is produced and negotiated, which I discuss as an anthropologist insider, is located in the dynamic of fielding consumer research on behalf of a corporate client. Insights gained in research, and in particular, fielding ethnographic research that is collaborative with the client and extended across several markets over time, is shaped and altered by agreed-upon interactions, which not only direct a client's best interest for his or her brand, but also are essential to sustaining relationships that continue future modes of production in the advertising industry.

This essay details the process of launching, conducting and gathering insights in a consumer research project that was commissioned by a client, and which contributed to enhancing client relations for the advertising agency. Outwardly, the project acknowledges that the series of negotiated interactions in research function to contribute to advancing a system of knowledge (i.e., learning more about consumer interaction with a product for the client's particular brand), but inwardly, such mediated relations between corporate anthropologist and client participant function to sustain and build relationships between the generalized client and the advertising agency. Fielding consumer research annually for a particular client of the ad agency is the conventional way for corporate clients to garner product insights and communication ideas for their advertising; but for the ad agency it is also an internal way to connect and sustain relations with their client. Little has been discussed about the ways that research 'facts' are shaped by the series of human interactions, and how data gathering itself functions to extend and enhance client relations as a form of constructed knowledge capital. When Sunderland and Denny note that research insights are not so much 'gathered' as they are 'produced' (2007: 51), they reference the interactions between interviewer and interviewee. In this essay, the idea of 'producing data' likewise applies to research relationships, but in addition to consumer and researcher, it extends the relations to those 
between 'insider' corporate anthropologist and representative client, which make such interactions 'strategic'. Recognizing power and positionality in collaborative research not so much brings to light relationships that are 'given, exchanged, or recovered' Foucault (1980: 89), as it reveals how power is exercised in action. Building on Goffman's (1974) strategic use of 'framing devices', this essay examines the construction and maintenance of relationships in advertising research, which use a concrete activity, such as fieldwork with clients, to help organize and control an experience that will frame discourses of power in an agreed upon narrative, which later on will influence the crafting of advertising campaigns. As such, a fieldwork event between client and anthropologist becomes, in terms of Goffman's (1974) frame analysis, a 'keyed transformation' of an enhanced model of and for a client-agency relationship.

\section{Advertising and the production of relationships}

While advertising's overt business is to produce advertisements for clients that consumers eventually see and hear, its less obvious business is recognized in enhancing human relationships. Specifically, advertising is in the business of producing and maintaining various forms of human relationships (Malefyt 2012; Malefyt and Morais 2012; Morais 2007; Moeran 1996, 2003, 2006). The outward production of advertisements works on two levels: creatively as a form of art, and economically as a type of business. Like other creative industries, advertising straddles the realm of style, aesthetics and art, but also hardcore commerce. Symbolic goods, such as advertising, 'are a two-faced reality, a commodity and a symbolic object' (Bourdieu 1993: 113). Advertising reflects two modes of producing relationships through art and commerce. First, advertising as a creative industry produces nothing tangible in itself, but rather links images, thoughts and ideas of the various products it advertises, with desirable lifestyles, values and modes of consumption for the consumer (Malefyt 2012; Miller 1997; Moeran 1996). In this, advertising produces associative relationships between ideas and things, various groups, institutions and individual people, within varying circumstances and changes in the political, economic and social milieu. Second, as a business, advertising agencies work hard and fast to maintain and guard their relationships with corporate clients against rival agencies that continually seek to poach and gain favor with coveted clients (Miller 1997: 160). This anxiety over losing business to rivals incites a 'paranoia of competition' over clients among advertisers, keeping agencies sharply peeled to marketing tactics of pricing, promotions, and strategic moves from competitors (Miller 1997: 166). Thus, from an external view, managing relations of art and commerce operates similar to Foucault's conception of the economic functionality of power (1980: 88) to the extent that ad agencies must simultaneously maintain relations of production in 
delivering business objectives for clients, while also maintaining an artistic advantage over rival advertising agencies through achieving artistic merits and creative awards (Malefyt 2013).

Nevertheless, from an internal and less apparent view, the world of advertising presents still another set of relationships to manage. The world of advertising is socially constructed (Malefyt 2003; Moeran 1996, Schudson 1984) so that ranking members of agencies are expected to administer client relations by managing impressions in various situations of engagement. As Goffman illustrates $(1959,1974)$, people in exchanges communicate not only information but also images of themselves. Just as the world of consumption is never neutral but about exchanges of positions and power (Douglas and Isherwood 1979), similarly advertising agency members 'seek an advantage of position' (Malefyt 2003: 140) from which to assess or define a situation of engagement, and respond in ways that are favorable to enhancing client relationships and positive outcomes. While planned events such as client-agency workshops, where brainstorming sessions over a client's brand and consumer can be better managed and controlled through impression management (Malefyt 2003, see also Moeran 1996), fielding consumer research in ethnography is far less manageable, and so relies on other means which are mutually collaborative such as framing experience.

Goffman defines frame analysis as a 'schemata of interpretation' (1974: 21), which offers a useful form of organization of social experience. As a primary frame of shared experience, our collaborative venture in ethnographic research creates a spectacular occasion between anthropologist and client, in which what is analyzed in consumer observations, interpretations, discussions and reading of 'sign images' around the field site, can be 'transformed' into agreed upon narratives of the consumer and brand that forge a bond between anthropologists and client. Moreover, this constructed narrative can be used back at the home office in front of clients and agency colleagues to shape later creative work and marketing tactics. 'Keying frames' (Goffman 1974: 43-44), such as in jointly experiencing research, have the effect of transforming a set of conventions of one activity that is already meaningful (our fieldwork endeavor), into something that is patterned on that activity (a constructed narrative), but used quite differently in another context (back at the office). This capacity to develop frames about our experience, and use in another context such as back at the office among agency colleagues, offers an irreplaceable model for demonstrating mutual collaboration and relationship-building.

From these views of relationship acquisition and maintenance, the work of advertising can be regarded as an on-going form of 'production of relations' that reveals an ever-changing structural alignment, in what Pierre Bourdieu would call a field of strategic relations and possibilities (1993: 33-39). According to Bourdieu (see also Malefyt 2012; Moeran 
$2003,2006)$, advertising exists in a relational field, occupying positions in a plane of possible position-taking strategies (1993: 33-34). Like a work of art, advertising is autonomous in its own right, and so is most favorable to symbolic power. Advertising produces no goods in and of itself, but rather converts commodity objects and services into symbolic images and narratives that are valued for and adapted to particular purposes and situations. Its position, then, is always relative to other factors (such as consumers, clients and rival agencies) that shift in a constantly changing field of artistic, political, social and economic production. Advertising thus produces a range of strategic relations in which to locate, perceive and identify opportunities (Goffman 1974) that enhance status with clients while avoiding faux pas that might undermine future relations.

This shifting process of position taking and of establishing and reasserting relations, both in continuous campaigns to consumers and repeated contact with corporate clients, acknowledges the potential and added value of conducting first-hand qualitative research for an ad agency vis-à-vis its corporate client. Ethnography is long, messy and laborintensive (Van Maanen 1998). It requires effort, time, distance and especially skilled interpretation of the results. But between corporate anthropologists and client participants, this lengthy process also yields abundant time and opportunity for the development of brand insights as well as fostering personal relations in the field, apart from corporate offices and everyday work routines. It also offers opportunity for openended observations of the fetishized object of corporations-the consumer (Arnould and Cayla 2013) — which can be discussed, negotiated, agreed upon and set forth, in building and sustaining clientagency relations. This development is additionally fostered by an ad agency insider perspective, where one doesn't just observe consumers in action and report 'facts' to a client, but rather interprets or 'translates' what is seen in terms of what is known of the personal needs of the client and client's brand-for a particular project and for other projects. In the case of anthropologist and client, what is observed, interpreted and agreed upon as 'facts' in research also constitute the foundation of the agreed upon relationship between the anthropologist researcher and the attending client.

\section{Background to research}

Agencies work hard and fast to be creative and please their corporate clients (Malefyt and Morais 2012: 35). They compete furiously against other rival agencies to garner client business (Miller 1997). Beyond delivering advertisements for their clients, another function of an ad agency typically involves conducting consumer research on behalf of the client's brands. Conducting consumer research is often a pre-condition to launching new advertising or revising current advertising (Steel 1998). 
Research seeks to uncover a new consumer insight or 'brand truth' about the way consumers use a product or service, and on which to develop a new brand message for advertising purposes. Many agencies offer their internal skills in marketing to clients as part of their service relationship, for which they may hold a range of strategic 'tools'-i.e., brand analyzers, brand optimizers, ethnographic insights, and so forth. Consumer research promises to deliver fresh insights to the client, and is often comparable to that of outside vendors in levels of methodological sophistication but at reduced costs (Malefyt 2009). It offers corporate clients a cost-effective way to employ high quality specialists to discover insights for their brand, and often with the promise that inside research can be better linked to the advertising work of the host agency by 'owning' the research and having available the researchers to further discuss with creative and other agency personnel.

Nevertheless, in-agency research has another hidden purpose which I discuss here. Conducting consumer research often involves indepth engagement over extended time and locations with the agency on behalf of the client's brand. Corporate marketers frequently ask for advertising agency input to inform new ways of gaining fresh perspectives on consumers for their brands. Consumer research is officially sanctioned several times a year to further develop new advertising ideas, measure brand recall, test out a new product idea, or discover a new way to communicate an old brand (Steel 1998). Each episode of research is an occasion for numerous strategic human interactions: stating research objectives, negotiating consumer targets and segments, deciding on consumer markets, writing screeners, developing discussion guides, setting agendas and schedules, fielding the research, reporting in, and agreeing upon results. All of these human 'touch points' comprise a series of interactions that must reach agreement to move brand research forward and launch future advertising campaigns. Indeed, facts collected are themselves shaped by human interactions so that data gathering becomes a form of social currency. The series of discussions, stated opinions, compromises and agreements between client and agency researcher offer a way for the advertising agency to create and sustain its clients with factual data, but also to develop and enhance human relations that mesh with formal systems of knowledge and power. This constructed knowledge and shared power serves as the basis for current and future relationships.

\section{Ethnographic research on a food brand}

I have worked as a corporate anthropologist in advertising for over fifteen years, and nine of those years as head of an ethnographic group, Cultural Discoveries, inside BBDO worldwide advertising. Our ethnographic practice provided a service that offered a variety of 
ethnographic methodologies under one umbrella. The range of methods in the agency services' 'toolkit' stressed the strategic function of the agency, positioning BBDO as more attractive to corporations seeking a full-service agency and more viable against other ethnographic vendors who competed for work from our clients.

In the fall of 2008, the client of an international food corporation sought our agency's help to conduct twelve ethnographic interviews. Agency personnel met at the client's Philadelphia corporate office to discuss research objectives, plan of execution, and the type of respondents we sought to interview. Our first step was to agree on the particular markets in which to carry out research. Since the topic to be investigated was people's attitudes towards healthier eating and since we wanted consumers who were at the leading edge of healthy eating trends, we sought towns and communities that were more progressive in their eating habits. We agreed on the markets of Portland, Oregon; Ann Arbor, Michigan; and suburban Philadelphia, Pennsylvania, for their strong product sales as well as for reaching a more sophisticated audience who were more likely to be aware of health issues for the brand. But key to this market knowledge and selection of fieldwork sites was awareness of another important relationship issue. Philadelphia as a location was also the 'backyard' to the client's extended headquarters, so more employees could take turns and attend research debriefings, or switch off with other employees to attend an ethnography session itself, without incurring extra travel cost to the company. Selecting the Philadelphia location put the lead brand manager in charge of the project in good standing with her corporate peers as a 'team player'. This was a subtle but important rationale for choosing one of the markets for conducting consumer research. The client and I could also defend our choice, arguing that the select segment of audience we were seeking existed sufficiently in this market for study.

The client and agency also discussed respondents who demonstrated moderate to strong healthy eating habits and lifestyles. Half were recruited as brand loyalists, and none rejected the brand under study, Healthy Brand (a pseudonym). From the corporation's point of view, research intended to gain a deeper understanding of specific attitudes, motivations and behaviors of consumers in relation to marketing Healthy Brand. Nevertheless, the client had also just completed a segmentation study that was quite expensive. Suggesting that we use the same segments again for the ethnography study helped to validate the client's effort (and expense) and the choices she made within the corporation. What we suggested was that there was no need to create new target definitions, but rather go with what she (the client) had previously developed, and recruit for our ethnography from there. This reinforced the client's previous work within the corporation and further tapped into the existing structures of knowledge within the corporation. 
Research for this project specifically sought to understand consumers' ideas and practices around healthful foods, and especially to uncover their attitudes and use of canned food. Given the food company's public commitment to reduce sodium across all its product lines as a health measure, insights around consumer perceptions of 'compromise' were important. Did a low-sodium benefit for Healthy Brand require much adjustment on behalf of consumers and their preference for taste? How would consumers accept the idea of sodium reduction across the food company's larger portfolio of products? The corporate team wanted Healthy Brand to be less about the reduction of negatives (i.e., lower sodium, fat, and cholesterol) and more about promoting a positive healthful message for consumers. The challenge for me as an anthropologist was to integrate these internal objectives of the client's brand with larger insights gained about cultural conceptions of health and wellness, and inform the client as to how they shaped values and beliefs toward their product.

After deciding on a research plan and specific consumer markets, we set up the fieldwork details and launched the project. I visited respondents' homes with the client along for observations, and we conducted two interviews per day for a little over a week. Interviews lasted about two and a half to three hours. At each interview, the client took specific interest in the most tangible and pragmatic markers of healthy living. She listened for the way people spoke about food labels, knew their list of ingredients in canned food, and cautioned about salt and preservatives. When respondents discussed the importance of fresh ingredients, the use of sea salt, and especially the lack of preservatives as specific markers of healthy eating, this struck a chord of opportunity for the client. She made a list of what items consumers wanted in their soups, and also what they wished to exclude. In another corporate project on food, unrelated to this study, the brand was in the midst of developing richer pictorial imagery for its product labels, both in the context of depicting images of food on the soup can and in the grocery store, where a serving dispenser rack was being restructured to be more visually appealing. This was 'inside information', which I, along with the agency account manager, suggested to the client that we incorporate into our interviews so that visual or pictorial information from the previous research could be used for respondents to comment on. Would the visual representations from professional artists who were designing new soup labels and shelf dispensers aid the respondents we interviewed in articulating their preferences? The client was pleased that this learning could carry over from one research project to other projects, and could affirm what she heard from respondents. This use of existing corporate knowledge in the current ethnography project would only have been possible from an insider's perspective of other research going on within the corporation, and also reveals the subjective relatedness of 'distinct' projects and the value of personal relations that can inform practices. 
As an anthropologist, I also heard from respondents during the interviews and probed further about the larger context in which they spoke about and referenced healthy eating. I observed the ways healthyoriented people described and practiced wellness in their lives, beyond healthy eating and food choices. Wellness was not a contained collection of described facts or stated goals that people aspired toward, such as getting to a certain weight or lowering cholesterol to a certain number (which the client was listening for). Rather, from the view of using cultural analysis, wellness indexed a broader set of dispositions that oriented consumers to generally practice healthier eating habits in certain ways, beneficial not only to one's self but also to others. Wellness in connection to others in the household and beyond assumed a sense of personal responsibility to act more diligently toward the environment (buy local produce), be attentive to the impact on one's surroundings (walk and recycle materials), and make decisions concerning what goes into one's body, how one feels, and what one puts out for exercise-all toward a goal of living life with a heightened sense of awareness and greater concern for others. Healthy consumers were pre-disposed not only towards 'good food,' but also to encompass a wider sense of appreciation that continually adjusted to the contingencies of the day, week, season and overall aging process in positive and reflective ways.

To find common ground between the client's interest in functional and observable brand features (clear labels, reduced sodium, functional benefits of food) and my interest as an anthropologist in larger cultural values (disposition towards personal responsibility, environmental concerns, life goals and so forth), the client and I discussed with each other the idea of good food offering multiple benefits that led to a healthier life. Furthermore, if a food brand, such as our client's, sought to minimize preservatives, salt, saturated fat, our story about the consumer could show consumers 'avoiding' problems in life and would be most relevant in communicating the 'brand facts.' In this way, we integrated ideas from the client's factual observations with larger cultural perspectives about the way healthy foods expressed a positive disposition and avoided problems in life, blending both material and lifestyle into a framed narrative about the consumer that reflected ideas for a positive advertising campaign. Insights from consumer research were thus produced as a frame that blended, incorporated and integrated anthropological and client specific agendas we both agreed upon in a narrative that could be described as data driven and also culturally driven in a way that synthesized a mutual agreement of perspectives.

\section{Discussion}

This case illustrates the ways in which conducting extended research together, such as ethnographic interviews with a corporate client, offers a 
means to organize and enhance experience in meaningful ways. This can also be understood to operate from an outside and inside perspective of relationship management.

From an outside perspective, just as goods in the consumer marketplace can be 'qualified' to adapt to change (Callon, et al 2004), insights, in terms of consumer data, likewise, can be adapted or 'qualified' in the relationships they help foster with corporate executives.

Adjustments to the consumer research plans, target markets, target segments and field data were small and subtle, but as Bourdieu notes of relationships, data are positional and change within the field, and so can help position relationships strategically as more valuable than data that an outsider might produce without insider knowledge or constructive interaction. The collaborative experience of conducting research itself is thus re-interpreted by advertising researchers, such as anthropologists, to be 'classified and reclassified' (Kopytoff 1986) into idiosyncratic categories that have relevance and utility for the relative communities and the individual members they serve. Insights are developed to strategically position the brand in the marketplace, but also to enhance client relations and foster ties within and between organizations and individuals, so that agreement on what was seen, spoken and emphasized in consumer research becomes an extension or in Goffman's terms, a transformation, of the relationship among advertising agency, anthropologist, and corporate client itself. In consumer research, then, multiple ideas and insights generated by any given project, either currently underway or previously developed, are potential sources of interaction as they are also sites for possible contestation and disagreement. The so-called hard data 'gathered' in research is indeed a source utilized not only to produce and maximize fresh perspectives on the brand, but also to negotiate (and even re-negotiate) relations with the corporate client.

From an inside perspective, the value of framing an experience to enhance client engagement ultimately shows the great importance and precariousness of relationship management in this line of work. Advertising agencies must demonstrate great relationship skills by continuously managing what Gregory Bateson (1972) calls a double bind. In a double bind, a person must obey two conflicting commands without leaving the situation. In conversation analysis, Deborah Tannen (1984: 2) discusses the double bind situation in which people must express their independent views, while at the same time seeking to connect and bond with others. This requires listening and asserting ideas while closely reading the other person. In advertising, asserting one's views in research, management and creative work is essential for an agency to stand out as different, unique and independent-'a thought leader'; yet agency personnel need to reach agreement among the various parties involved in media, management, and creative work to move projects 
forward. Compounding this issue, a client's collective team may consist of brand manager, product designer, media specialist, sales representative, distribution manager, among other departments and roles, where reaching consensus is critical. An agency artifact of this double bind in relationship management can be noted in the photograph of a sign placed in our agency's main conference room.

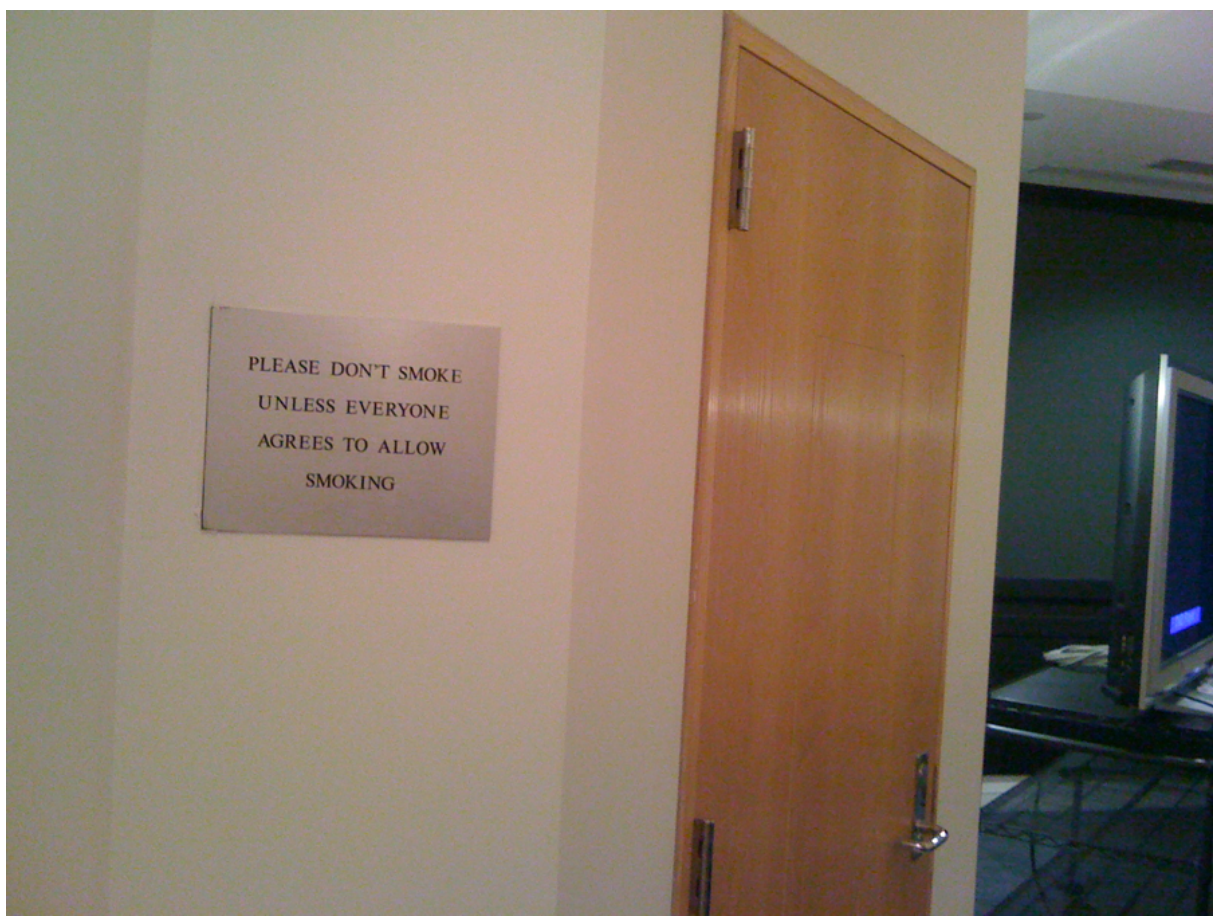

Figure 1: 'Double bind' at work in BBDO Conference room (picture by author)

This photo depicts the double bind at work, such as in making a forward statement that requests people not to smoke, yet at the same time acknowledging that a client may wish to smoke, and so allowing exceptions. Agencies are thus constantly attempting to achieve both ends, standing out as different, but fitting in consensually by applying impression management, symbolic representations, and framed experiences in their relationship work.

\section{Conclusion}

Relationship management is shown here to be the central raison d'être of advertising in its field of cultural production. In advertising, knowledge, power and human relationships are socially constituted in a shifting field of relations, relative to other relations as a whole. The discovery of brand insights in advertising research and the call to continually field research with the client in-tow, thus provides a proxy for the agency-client relationship, not only in a data-gathering factual sense, but also in a sense of framing mutual experiences and reaching an agreement over terms 
that validate the very interaction and engagements between both parties. Research on a brand's relationship to consumers offers a system of distinctive properties, variables and qualities, which can be situated relative to other positions and relations (Bourdieu 1993: 30). Insights from research that are agreed upon between client and agency, then, are nothing other than a realignment of the distribution of knowledge capital and power of specific qualities and properties, which govern the structure of the overall relationship between client and agency. Every position taking is thus defined in relation to the 'spaces of possibles' from which it receives its distinctive value. In this case, an anthropologist's inside perspective on client issues, beyond the research in question, affords better attuning to corporate issues and blended outcomes, and yields stronger interpersonal relationships which create regimes of value in social and personal capital, equal to economic capital for an advertising agency. Advertising agencies are thus constructed on relations of mutual agreement, and agreement in relationships takes the form of knowledge capital in a market system of possibilities.

\section{References}

Arnould, Eric and Julian Cayla 2013 'Consumer fetish.' Paper presented at the EPIC conference, London, Sept 15-18.

Bateson, Gregory 1972 Steps to an Ecology of Mind. New York: Ballentine.

Bourdieu, Pierre 1993 The Field of Cultural Production. New York: Columbia University Press.

Callon, Michel, Meadel, Cecile, and Rabeharisoa, Vololona 2004 'The Economy of Qualities.' In A. Ash and N. Thrift (eds.), The Blackwell Cultural Economy Reader, pp. 58-79. Malden: Blackwell.

Douglas, Mary and Isherwood, Baron 1979 The World of Goods: Towards an Anthropology of Consumption. London: Routledge.

Foucault, Michel 1980 Power/Knowledge: Selected Interviews \& Other Writings 1972-1977. New York: Pantheon.

Goffman, Erving 1959 The Presentation of Self in Everyday Life. Garden City, NY: Doubleday Anchor Books.

1974 Frame Analysis: An Essay on the Organization of

Experience. Boston: Northeastern University Press.

Kopytoff, Igor 1986 'The Cultural Biography of Things: Commoditization as Process.' In A. Appadurai (ed.), The Social Life of Things: Commodities in Cultural Perspective, pp. 64-91. Cambridge, U.K.: Cambridge University Press. 
Malefyt, Timothy de Waal 2003 Models, Metaphors and Client Relations: The Negotiated Meanings of Advertising,' in T. de Waal Malefyt and B. Moeran (eds.), Advertising Cultures, pp. 139-163. Oxford: Berg. 2009 'Understanding the rise of consumer ethnography: branding techno-methodologies in the new economy.' American Anthropologist 111(2): 201-210.

2012 'Writing advertising: the production of relationships in historical review.' In Journal of Business Anthropology 1(2): 218-239. 2013 'Celebrity Status, Names, and Ideas in the Advertising Award System,' in B. Moeran and B. Christensen (eds.), Exploring Creativity, pp. 191-210. Cambridge: Cambridge University Press, Malefyt, Timothy de Waal and Morais, Robert J. 2012 Advertising and Anthropology: Ethnographic Practice and Cultural Perspectives. Oxford: Berg.

Morais, Robert J. 2007 'Conflict and confluence in advertising meetings,' in Human Organization, 66(2): 150-59.

Miller, Daniel 1997 Capitalism: An Ethnographic Approach. Oxford, UK: Berg.

Moeran, Brian 1996 A Japanese Advertising Agency. Honolulu: University of Hawaii Press.

2003 'Celebrities and the name economy.' In N. Dannhaeuser and C. Werner (eds.), Anthropological Perspectives on Economic Development and Integration, pp. 299-321. Amsterdam: Elsevier. Vol. 22. 2006 Ethnography at Work. Oxford: Berg.

Schudson, Michael 1984 Advertising: The Uneasy Persuasion. New York: Basic.

Steel, Jon 1998 Truth, Lies and Advertising: The Art of Account Planning. New York: Wiley.

Sunderland, Patricia, and Denny, Rita 2007 Doing Anthropology in Consumer Research, Walnut Creek, CA: Left Coast Press.

Tannen, Deborah 1984 Conversational Style: Analyzing Talk among Friends. Norwood, NJ: Ablex Publishing Corp.

Van Maanen, John 1988 Tales of the Field: On Writing Ethnography. Chicago: University of Chicago Press.

Timothy de Waal Malefyt is Clinical Associate Professor of Marketing at Fordham University, Gabelli school of Business, in NYC. Previously he was VP, Director of Cultural Discoveries at BBDO advertising in NYC, and Senior Account Planner, at D'Arcy, Masius, Benton \& Bowles in Detroit, where he worked on Cadillac. He is co-editor of Advertising Cultures (2003), and co-author of Advertising and Anthropology (2012). 